\title{
Determinants of cervical cancer screening via Pap smear among female staff in a tertiary hospital in Niger-Delta of Nigeria
}

\author{
Peter A. Awoyesuku*, Basil O. Altraide, Dagogo A. Mac Pepple
}

Department of Obstetrics and Gynecology, Rivers State University Teaching Hospital, 6-8 Harley Street, Old G.R.A, Port-Harcourt, P.M.B, 5064, Nigeria

Received: 02 August 2019

Accepted: 13 September 2019

*Correspondence:

Dr. Peter A. Awoyesuku,

E-mail: pawoyesuku@yahoo.co.uk

Copyright: (C) the author(s), publisher and licensee Medip Academy. This is an open-access article distributed under the terms of the Creative Commons Attribution Non-Commercial License, which permits unrestricted non-commercial use, distribution, and reproduction in any medium, provided the original work is properly cited.

\begin{abstract}
Background: Cervical cancer remains a leading cause of death among women in the developing world, with poor prognosis attributed to lack of awareness about the disease and its prevention. Hospital workers' attitude and practice to such an issue might positively or negatively influence people they come into contact with. This study is to assess the determinants of cervical cancer screening via Pap smear among Female Staff in a Tertiary Hospital in Nigeria.

Methods: A hospital-based cross-sectional study was conducted between September and November 2015 . A structured self-administered questionnaire was used to collect data from 265 female hospital workers on sociodemographic characteristics (age, parity, educational level and occupational category) and awareness and utilization of Pap smear test. The data obtained were analyzed using SPSS version 20.0.

Results: Of the 265 respondents, only $40(15.1 \%)$ had Pap smear test done at least once previously. Bivariate analysis of socio-demographic factors and Pap smear test uptake among the respondents was statistically significant for younger maternal age $\leq 35$ years, not being married, higher educational level, professional occupation category and awareness of Pap smear. However, only maternal age, marital status and awareness of Pap smear remain statistically significant after multivariate analysis.

Conclusions: Uptake of Pap smear test as a screening test for cervical cancer is low among female hospital workers. Identified determinants of cervical cancer screening via Pap smear test were younger age $\leq 35$ years, not being married, higher educational level, professional occupational category and awareness of Pap smear.
\end{abstract}

Keywords: Cervical cancer, Determinants, Niger-Delta, Pap smear, Screening uptake, Tertiary hospital

\section{INTRODUCTION}

Cervical cancer remains a major health issue among women in developing countries especially in Sub-Saharan Africa. It is the second most common malignancy in women worldwide. ${ }^{1}$ However, it is the most common cause of cancer related morbidity and mortality in women in the developing countries. ${ }^{2}$ In Nigeria, an estimated 10,000 new cases of cervical cancer and 8,000 deaths due to the disease are recorded among women yearly. ${ }^{3}$ Moreover, Nigeria has an estimated five-year prevalence of $21.6 \%$ for cervical cancer as published in GLOBOCAN fact sheet of $2012 .^{4}$

Cervical cancer is the commonest malignancy of the female genital tract in Nigeria, accounting for $70.5 \%$ of gynecological malignancies in Maiduguri, $59.2 \%$ in Kano, $77 \%$ in Zaria, $60 \%$ in Ilorin, $74 \%$ in Jos and $74.6 \%$ in Benin. ${ }^{5-10}$ Data from Kenya, Zimbabwe, and Ghana have shown that cervical cancer accounted for $57.8 \%, 70$ $80 \%$ and $80 \%$ of gynecological cancers respectively. ${ }^{11,12}$ Papanicolaou (Pap) smear cytology screening method to 
identify precancerous lesions has helped in achieving massive reduction in the burden of cancer of the cervix especially in the developed countries. ${ }^{13,14}$ Other less invasive techniques have been developed for rapid screening of cancer of the cervix, and although they are faster and less cumbersome, they have been discovered to be less sensitive compared to cytological examination through Pap smear. ${ }^{15}$ The Pap smear test is readily available in our Centre on physician referral and compulsorily for all postpartum mothers at the six weeks visit.

Although screening is a known cost-effective strategy used in reducing the burden of cervical cancer worldwide, its uptake particularly in developing countries is still abysmal. ${ }^{16,17}$ Previous reports in Nigeria have shown that the major factors responsible for the high case fatality associated with this otherwise preventable tumour are poor knowledge about the disease and possible preventive measures against it. ${ }^{18,19}$

Also, some studies have identified socio-demographic predictors of cervical cancer knowledge and screening among various populations. The factors with positive correlates identified include being married, having higher income (good occupation), longer years of education and age above 30 years..$^{20-23}$ These factors however vary among different populations. Seow et al concluded that the means of increasing awareness of cervical cancer and acceptance of Pap smear should be culture specific. ${ }^{22}$

Health care workers were anticipated to be knowledgeable about cervical cancer screening compared to non-health care workers and consequently to persuade cervical cancer screening among women. ${ }^{24}$ Their attitude and practice to such an issue might positively or negatively influence people they come into contact with, since they are strategically positioned to interact with people from various walks of life. Findings in them may give an insight into how they affect the larger society.

$\mathrm{Au}$ therefore decided to assess the determinants of cervical cancer screening via Pap smear among Female Staff in our hospital.

\section{METHODS}

This descriptive, hospital based, cross-sectional, questionnaire-based study of 265 female health workers in the Rivers state university teaching hospital was carried out between September and November 2015. Female health workers refer to all Professional health staff of the hospital; Doctors, Nurses, Laboratory scientists, Pharmacists and Physiotherapist; and NonProfessional staffs such as administrative staff, Cleaners, Maids and Porters.

A structured, self-administered questionnaire was used for this study. The questionnaire contained questions which sought to determine the socio-demographic characteristics of the respondents (age, parity, educational level and occupational category) and their awareness \& utilization of Pap smear as a screening device for cancer of the cervix.

Purpose of the study and assurances of confidentiality were fully explained to the participants and research assistants who assisted in data collection and the participants were asked for their voluntary participation before administration of the questionnaires. Only those above 18 and sexually active were included. A total of 285 female workers of the hospital on the Nominal role were identified at their workplaces and given the questionnaires. 20 workers who did not voluntarily agree to participate and did not return their questionnaire were excluded. 265 volunteered, properly completed and returned their questionnaires; these were included and formed the basis of the analyses.

\section{Statistical analysis}

The collected questionnaires were checked manually for its completeness, coded and entered into Microsoft Excel, then exported to SPSS version 20.0 for statistical analysis. The Pap smear test uptake among respondents and independent variables were expressed in percentages.

Bivariate analysis employed Chi square/Fisher's exact statistics in determining significant differences in the demographic pattern. Statistical significance was set at $\mathrm{P}<0.25$ for bivariate analysis. Statistically significant variables on bivariate analysis were entered into a multivariate analysis model. Multivariate analysis was done using unconditional binary logistic regression model. The dependent variable was Pap smear test uptake (categorized as Yes/No) while the demographic characteristics comprised the independent variables. Odds ratio and $95 \%$ confidence intervals were determined and $\mathrm{P}<0.05$ following multivariate analysis were considered statistically significant.

\section{RESULTS}

Of the 265 respondents, only 40 (15.1\%) had done a Pap smear test at least once previously in their life, while 225 $(84.9 \%)$ had not done Pap smear previously Figure 1.

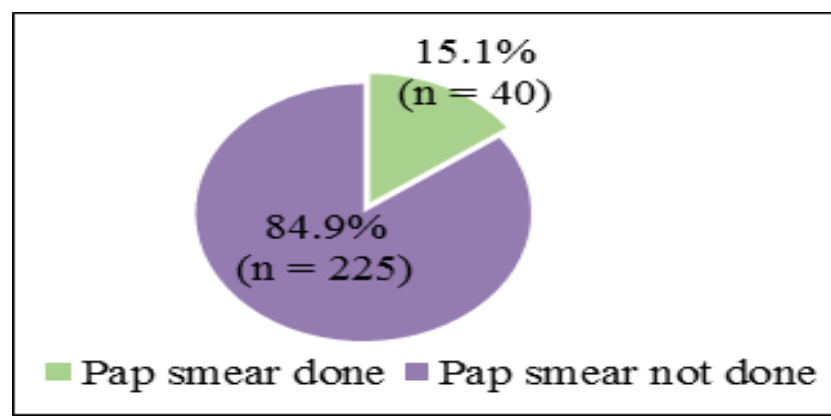

Figure 1: Distribution of Pap smear testing among the study participants. 
Table 1: Bivariate analysis of factors associated with Pap smear screening among the study participants.

\begin{tabular}{|c|c|c|c|c|}
\hline & \multicolumn{4}{|c|}{ Pap smear screening } \\
\hline Variables & Yes, n (\%) & No, $n(\%)$ & Total, n (\%) & Crude OR 95\% CI \\
\hline \multicolumn{5}{|l|}{ Age category } \\
\hline$\leq 35$ years & $13(8.1)$ & $147(91.9)$ & $160(100.0)$ & $0.26(0.13-0.52)$ \\
\hline$>35$ years & $27(25.7)$ & $78(74.3)$ & $105(100.0)$ & 1 \\
\hline \multicolumn{5}{|c|}{ Chi-Square $=15.304 ; P=0.0001^{*}$} \\
\hline \multicolumn{5}{|l|}{ Marital status } \\
\hline Single & $7(5.6)$ & $118(94.4)$ & $125(100.0)$ & $0.19(0.08-0.45)$ \\
\hline Married & $33(23.6)$ & $107(76.4)$ & $140(100.0)$ & 1 \\
\hline \multicolumn{5}{|c|}{ Chi-Square $=16.642 ; P=0.0001 *$} \\
\hline \multicolumn{5}{|l|}{ Educational level } \\
\hline Below tertiary & $2(6.1)$ & $31(93.9)$ & $33(100.0)$ & $0.33(0.08-1.44)$ \\
\hline Tertiary and above & $38(16.4)$ & 194 (83.6) & $232(100.0)$ & 1 \\
\hline \multicolumn{5}{|c|}{ Fisher's exact $P=.191^{*}$} \\
\hline \multicolumn{5}{|c|}{ Occupational status } \\
\hline Professional & 37 (16.6) & $186(83.4)$ & $223(100.0)$ & $2.59(0.76-8.81)$ \\
\hline Non-professional & $3(7.1)$ & $39(92.9)$ & $42(100.0)$ & 1 \\
\hline \multicolumn{5}{|c|}{ Chi-Square $=2.462 ; P=0.117^{*}$} \\
\hline \multicolumn{5}{|c|}{ Knowledge on pap smear for cervical cancer screening } \\
\hline Yes & 36 (19.4) & $150(80.6)$ & $186(100.0)$ & $4.50(1.54-13.11)$ \\
\hline No & $4(5.1)$ & 75 (94.9) & $79(100.0)$ & \\
\hline Chi-Square $=8.83$ & $=0.003 *$ & & & \\
\hline
\end{tabular}

Table 2: Multivariate analysis of factors associated with ( $\mathbf{P}<0.25$ on bivariate analysis) Pap smear screening among the study participants.

\begin{tabular}{|c|c|c|c|c|}
\hline Variables* & Coefficient (B) & Odds ratio (OR) & $95 \% \mathrm{CI}$ & p value \\
\hline \multicolumn{5}{|l|}{ Age category } \\
\hline$\leq 35$ years & 1.177 & 3.244 & $1.45-7.26$ & $0.004 *$ \\
\hline$>35$ years ${ }^{R}$ & & 1 & 1 & \\
\hline \multicolumn{5}{|l|}{ Marital status } \\
\hline Single & 1.382 & 3.984 & $1.55-10.22$ & $0.004 *$ \\
\hline Married ${ }^{R}$ & & 1 & 1 & \\
\hline \multicolumn{5}{|l|}{ Educational level } \\
\hline Below tertiary & 0.136 & 1.145 & $0.18-7.32$ & 0.886 \\
\hline Tertiary and above ${ }^{R}$ & & 1 & 1 & \\
\hline \multicolumn{5}{|l|}{ Occupational status } \\
\hline Professional & 0.504 & 1.655 & $0.35-7.76$ & 0.523 \\
\hline Non-professional ${ }^{R}$ & & 1 & 1 & \\
\hline \multicolumn{5}{|c|}{ Knowledge on pap smear for cervical cancer screening } \\
\hline Yes & 1.827 & 6.216 & $1.85-20.87$ & $0.003 *$ \\
\hline $\mathrm{No}^{R}$ & & 1 & 1 & \\
\hline
\end{tabular}

*Statistically significant $\mathrm{P}<0.05$, R: Reference category, CI: Confidence interval

The socio-demographic characteristics and awareness of Pap smear as a cervical cancer screening procedure (independent variables) are shown in Figure 2. A majority of the respondents $70.2 \%$ were aware of Pap smear, were aged $\leq 35$ years $(60.4 \%)$, were married $(52.8 \%)$, had tertiary education $(87.5 \%)$ and were professionals $(84.2 \%)$.
Bivariate analysis of factors associated with Pap smear screening among the study participants is as shown in Table 1. Using Chi-square test and Fisher's exact score as test of significance at $\mathrm{P}<0.25$, younger maternal age, not being married, having higher education, having a professional occupation and having knowledge of Pap smear test were statistically significant. 


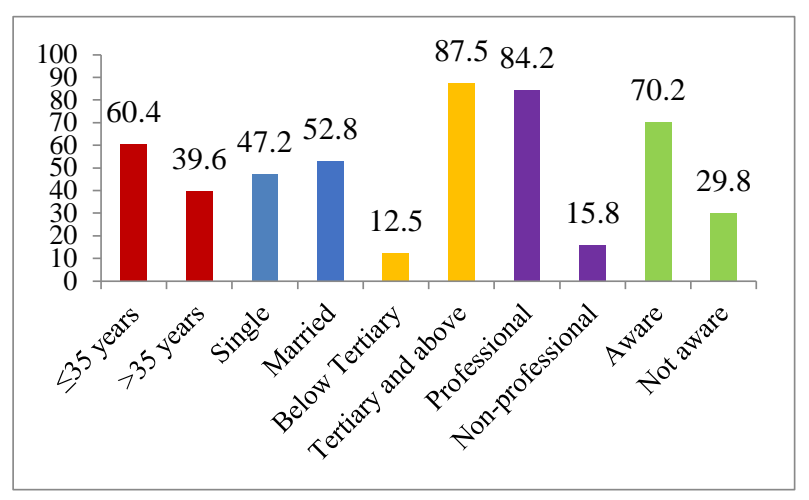

Figure 2: For distribution of independent variables in the study.

However, only younger maternal age, not being married and having knowledge of Pap smear remain statistically significant after multivariate analysis (Table 2). Women 35 years and younger were more likely to have Pap smear test done than those older $\mathrm{p}=0.004$ (odds ratio $=1.177$; 95\% CI: 1.45-7.26). Likewise, single women were more likely to uptake testing than married women $\mathrm{p}=0.004$ (odds ratio $=1.382 ; 95 \%$ CI: $1.55-10.22$ ). Those with knowledge of Pap smear (awareness) were about twice more likely to do a Pap smear test than those without knowledge $\mathrm{p}=0.003$ (odds ratio $=1.827$; 95\% CI: 1.85 20.87).

\section{DISCUSSION}

The uptake of Pap smear among the respondents in this study was low $(15.1 \%)$. This finding is in keeping with what literatures had reported in different parts of the developing world and among varied population. ${ }^{16,17,23}$ However, Assoumou et al reported that $65.1 \%$ of the women interviewed in Gabon had gone for Pap smear test before. $^{25}$ The reason for this higher figure in the Gabonese study was attributed to the higher socioeconomic characteristics of the respondents; with $63 \%$ having tertiary education and $51.6 \%$ being employed. The lower uptake in our respondents, despite similar characteristics, may be due to sociocultural barriers, lack of physician referral and poor risk perception, as seen in other studies of Nigerian health personnel. ${ }^{2,8,23,26}$

The sociodemographic factors with positive correlates identified in previous studies as determinants of knowledge and uptake of Pap smear include being married, having higher income (good occupation), longer years of education and age above 30 years. ${ }^{20-23}$

In this study, younger maternal age ( $\leq 35$ years), not being married, having higher education (tertiary education), having a professional occupation (and hence good income) and having knowledge of Pap smear test were statistically significant. Unlike our findings, Ayide et al and Siahpush et al found that single women and those under 30 years are less likely to know about the disease and Pap smear test, and are less likely to make themselves available for cervical cancer screening as shown by previous studies. ${ }^{27,28}$ The difference may be due to the study population, ours being among health workers.

The correlation between higher levels of education and income and utilization of cervical cancer screening seen in this study was similar to findings by Skaer et al and Bukari et al but not in the findings by Ayinde et al among market women..$^{20,23,27}$ Educational and occupational status of people often determines awareness level about a particular health condition and their financial capability to access health care.

Studies have reported high level of awareness of cervical cancer and cervical cancer screening tests among health workers in Nigeria, as seen in Abuja and Ilorin. ${ }^{28}$ Previous reports in Nigeria have shown that the major factors responsible for the high case fatality associated with this otherwise preventable tumour are poor knowledge about the disease and possible preventive measures against it. ${ }^{18,19}$ Awareness about cervical cancer and screening with Pap smear was a significant determinant of uptake in this study.

This study was limited by its cross sectional, hospitalbased nature and convenience sampling; It was also limited by the fact that the study was conducted in an urban area. Community based study in these regards is recommended and this should include rural areas.

\section{CONCLUSION}

The uptake of Pap smear test as a screening test for cervical cancer is low among female hospital workers. Identified determinants of cervical cancer screening via Pap smear test were younger age $\leq 35$ years, not being married, higher educational level, professional occupational category and awareness of Pap smear. Since this group of workers unconsciously and passively act as role models in health-related attitude and behaviour to members of the larger society, they need to be encouraged on the importance of taking up screening so that they can convince other women they come in contact with in the course of discharging their duties.

On a larger scale, continued public health education is important on the preventable nature of invasive cervical cancer through Pap smear test. However, as there are yet no established systematic screening programmes in most developing countries, increased opportunistic screening should be intensified in an effort to reduce the burden of cervical cancer in the developing world.

\section{ACKNOWLEDGMENTS}

Authors would like to acknowledge the contributions of the interns and resident doctors (research assistants) who 
voluntarily assisted in distributing and retrieving the questionnaires.

Funding: No funding sources Conflict of interest: None declared

Ethical approval: Not required

\section{REFERENCES}

1. Parkin DM, Bray F, Ferlay J, Pisani P. Global cancer statistics, 2002. Cancer J Clin. 2005;55:74-108.

2. Olaniyan OB, Agbogoroma OC, Ladipo OP. Knowledge and practice of cervical screening among female health workers in government hospitals in Abuja Metropolis Nigeria. Trop J Obstet Gynaecol. 2000;17:18-20.

3. Airede L, Onakewhor J, Aziken M, Ande A, Aligbe J. Carcinoma of the uterine cervix in Nigerian women: the need to adapt a national preventive strategy. Sahel Med J. 2008;1:1-11.

4. GLOBOCAN. International agency for research on cancer. Fact sheet, 2012.

5. Kyari O, Nggada H, Mairiga A. Malignant tumours of female genital tract in North-East Nigeria, East Afr Med J. 2004;81:142-5.

6. Galadanci HS, Jido TA, Mohammed AZ, Uzoho CC, Ochicha O. Gynecological malignancies at Aminu Kano teaching hospital: a five-year review (19972001). Trop J Obstet Gynaecol. 2002;19(suppl 2):10.

7. Mohammed A, Avidime S, Oluwole OP, Ahmed SA. Malignant tumours of female genital tract in Zaria, Nigeria. An analysis of 513 cases (1993-2003). Trop J Obstet Gynaecol. 2005;22:S45.

8. Aboyeji PA, Ijaiya MA, Jimoh AA. Knowledge, attitude and practice of cervical smear as a screening procedure for cervical cancer in Ilorin, Nigeria. Trop J Obstet Gynaecol. 2004;21:114-7.

9. Mutihir JT. Common gynaecological conditions at the Jos university teaching hospital, North-Central Nigeria. Trop J Obstet Gynaecol. 2005;22(Suppl 1):S7.

10. Gharoro EP, Abedi HO, Okpere EE. Carcinoma of the cervix: Aspects of clinical presentation and management in Benin city. Int $\mathbf{J}$ Gynaecol Obstet. 1999;67:51-3.

11. Chirenji ZM, Rusa-Kaniko S, Kirumbi I, Ngwalle EW, Makuta-Tiebere P, Kaggwa S, et al. Situation analysis for cervical cancer diagnosis and treatment in East Central and Southern African countries. Int J Public Health. 2001;79:127-32.

12. NkyeKyer K. Pattern of gynaecological cancers in Ghana. East Afr Med J. 2000;77:534-8.

13. World Health Organization (WHO). Comprehensive cervical cancer control: a guide to essential practice $2^{\text {nd }}$ ed. WHO, Geneva. 2014. Available at: https://apps.who.int/iris/bitstream/handle/10666/1447 85/9789241548953. Accessed on $12^{\text {th }}$ July 2019.

14. Stewart BW, Kleihues P. Cancers of the female reproductive tract. World Cancer Report.
International Agency for Research on Cancer. IARC Press, Lyon, France. 2003.

15. Satyanarayana I, Asthana S, Bhambani S, Sodhani P, Gupta S. A comprehensive study of cervical cancer screening in a rural community setting of North India. Indian J of Cancer. 2014;2:124-8.

16. Jeronimo J, Bansil P, Lim J. A multi-country evaluation of care, HPV testing, visual inspection with acetic acid and Papanicolaou testing for the detection of cervical cancer. Int $\mathbf{J}$ of Gynaecol Cancer. 2014;3:576-85.

17. Hoque M, Hague E, Kader SB. Evaluation of cervical cancer screening programme at a rural community of South Africa. East Afr J of Public Health. 2008;2:111-6.

18. Ayinde OA, Omigbodun AO. Knowledge, attitude and practices related to prevention of cancer of the cervix among female health workers in Ibadan. J Obstet Gynaecol. 2003;1:55-8.

19. Ajayi IO, Adewole IF. Knowledge and attitude of General Outpatient attendants in Nigeria to cervical screening. Centr Afr J Med. 1998;1:25-30.

20. Skaer TL, Robinson LM, Sclar DA, Harding GH. Cancer screening determinants among Hispanic women migrant health clinics. J Health Care Poor Underserved. 1996;4:338-54.

21. Claeys P, Gonzalez C, Gonzalez M, Page H, Bello RE, Temmerman M. Determinants of cervical cancer screening in a poor area: results of a populationbased survey in Rivas, Nicaragua. Trop Med Int Health. 2002;11:935-41.

22. Seow A, Wong ML, Smith WC, Lee HP. Beliefs and attitudes as determinants of cervical screening: a community-based study in Singapore. Prev Med. 1995;2:134-41

23. Bakari M, Takai IU, Bukar M. Awareness and utilization of Papanicolaou smear among health care workers in Maiduguri, Nigeria. Niger J Basic Clin Sci. 2015;12:34-8.

24. Gebreegziabher M, Asefa NG, Berhe S. Factors affecting the practices of cervical cancer screening among female nurses at public health institutions in Mekelle Town, Northern Ethiopia, 2014: a cross sectional study. J Cancer Res. 2016;2016:7.

25. Assoumou SZ, Mabika BM, Mbiguino AN, Mouallif M, Khattabi A, Ennaji MM. Awareness and knowledge regarding cervical cancer, Pap smear screening and human papillomavirus infection in Gabonese women. BMC Women's Health. 2015;37. Available at: https://dx.doi.org/10.1186/s12905-0150193-2.

26. Idowu A, Olowookere SA, Fagbemi AT, Ogunlaja OA. Determinants of cervical screening uptake among women in Ilorin, North-Central Nigeria: a community-based study. J Cancer Epidemiol. 2016.

27. Ayide OA, Ogunbode OO, Adebayo OJ. Determinants of cervical cancer knowledge and the utilization of screening among a Nigerian female population. Trop J Obstet Gynaecol. 2005;1:21-4. 
28. Siahpush M, Singh GK. Sociodemographic predictors of Pap smear test receipt, currency and knowledge among Australian women. Prev Med. 2002;4:362-8.
Cite this article as: Awoyesuku PA, Altraide $\mathrm{BO}$, Mac Pepple DA. Determinants of cervical cancer screening via Pap smear among female staff in a tertiary hospital in Niger-Delta of Nigeria. Int J Reprod Contracept Obstet Gynecol 2019;8:4285-90. 